\title{
FATE OF INGESTED ESCHERICHIA COLI IN NORMAL PERSONS
}

\author{
E. Mary Cooke*, Ira G. T. Hettiaratchy† and A. C. Buck $\ddagger$ \\ Department of Bacteriology, St Bartholomew's Hospital, London
}

THE factors affecting strains of Escherichia coli carried in the bowel of man are poorly understood. Some workers have found the coliform population of the bowel to be relatively stable (Sears, Brownlee and Uchiyama, 1950), but others have shown that the faecal coliform flora may change (Cooke, Ewins and Shooter, 1969; Wiedmann and Knothe, 1969) and this, in one instance, has been related to the ingestion of large numbers of E. coli in food (Cooke et al., 1970). It has also been postulated that these strains of $E$. coli may be of animal origin, and may reach the prepared food by cross-contamination in the kitchen (Shooter et al., 1970).

It is not known whether all strains of ingested $E$. coli will establish themselves in the bowel, what numbers if ingested will be detectable in the faeces, and whether strains from different sources or of different serotype or colicine type behave differently. The experiments reported here were performed in an attempt to answer these questions.

\section{MATERIALS AND METHODS}

Volunteers. These were one man and two women who were members of the laboratory staff. They were aged 33-37 yr, and had no known abnormality of the gastro-intestinal tract. They were not receiving antibiotics and were eating a normal mixed diet. The food eaten by these volunteers was not examined for the presence of coliform bacteria.

$E$. coli strains for ingestion. Twelve strains of $E$. coli, some of human and some of animal origin, were ingested. The sources, serotype, antibiotic sensitivity, colicinogenicity, and colicine sensitivity of the strains are shown in table I.

The human strains were isolates from normal faeces of patients in a medical ward. The four animal strains were faecal isolates from healthy animals.

Except on two occasions, the strains were rendered resistant to streptomycin or nalidixic acid in the laboratory before they were ingested. From a 5 -hr broth culture of the test strain $0.5 \mathrm{ml}$ was added to $200 \mathrm{ml}$ of cold milk which was drunk in the late afternoon, $3-4 \mathrm{hr}$ after the last meal. The numbers of organisms ingested, determined by surface-viable counts on blood agar, ranged from $10^{5}$ to $10^{8}$ except that on one occasion $10^{11}$ freeze-dried organisms were ingested.

Examination of faeces. Specimens of faeces were examined on at least three occasions before ingestion of $E$. coli, and on three occasions after its disappearance. In each experiment, every specimen of faeces passed was examined.

Specimens were examined as soon as they were passed or were stored for up to $24 \mathrm{hr}$ at

Received 19 Oct. 1971; accepted 12 Feb. 1972.

* Present address: Group Laboratory, County Hospital, York, YO3 7PG.

$\uparrow$ Present address: Medical Research Institute, Colombo 8, Ceylon.

$\ddagger$ Present address: Department of Pathology, Princess Margaret Hospital, Swindon.

3. MED. MICROBIOL.-VOL. 5 (1972)

361 
$4^{\circ} \mathrm{C}$ before examination. Three grammes of faeces were placed in $10 \mathrm{ml}$ of quarter-strength Ringer's solution in a 30-ml screw-capped container and homogenised by shaking for $2 \mathrm{~min}$. on a Griffith flask-shaker. The total coliform count and the number of resistant organisms were determined by surface-viable counts from ten-fold serial dilutions of the faecal suspension on MacConkey agar and on MacConkey agar containing either $20 \mu \mathrm{g}$ per ml of nalidixic acid or $15 \mu \mathrm{g}$ per $\mathrm{ml}$ of streptomycin.

The identity of resistant organisms was confirmed by serotyping except in the case of three strains that were untypable with the antisera used. On two occasions the ingested strain was not made antibiotic resistant and was identified in one case by slide agglutination using OK antiserum prepared against the organism, and in the other by typing ten colonies from the MacConkey medium with $\mathrm{O}$ antisera.

TABLE I

Ingested strains of E. coli: their sources and properties

\begin{tabular}{|c|c|c|c|c|c|}
\hline $\begin{array}{c}\text { Strain } \\
\text { number }\end{array}$ & Origin & Serotype & Colicinogenicity & $\begin{array}{l}\text { Sensitivity to } \\
\text { colicines }\end{array}$ & $\begin{array}{l}\text { Pattern of } \\
\text { sensitivity to } \\
\text { antibacterial } \\
\text { drugs }\end{array}$ \\
\hline $\begin{array}{l}1 \\
2 \\
3 \\
4 \\
5 \\
6 \\
7 \\
8\end{array}$ & $\begin{array}{l}\text { Human } \\
\text { Human } \\
\text { Human } \\
\text { Human } \\
\text { Human } \\
\text { Human } \\
\text { Human } \\
\text { Human }\end{array}$ & $\begin{array}{l}\text { O11 } \\
\text { O11 } \\
\text { O4 } \\
\text { O4 } \\
\text { O2 } \\
\text { O6 } \\
\text { O12 } \\
\text { Rough }\end{array}$ & $\begin{array}{l} \pm \\
\pm \\
+ \\
+ \\
+ \\
+ \\
\pm \\
-\end{array}$ & $\begin{array}{c}\mathrm{K}, \mathrm{H}, \mathrm{E} 2 \\
\mathrm{H}, \mathrm{E} 2 \\
\overline{\mathrm{K}} \\
\overline{\mathrm{K}, \mathrm{E} 2} \\
\overline{\mathrm{V}, \mathrm{A}, \mathrm{B}, \mathrm{K}}\end{array}$ & $\begin{array}{c}\text { FS } \\
\text { FS } \\
\text { FS } \\
\text { FS } \\
\text { FS } \\
\text { FS } \\
\text { R/Su } \\
\text { R/Su, T }\end{array}$ \\
\hline $\begin{array}{r}9 \\
10 \\
11 \\
12\end{array}$ & $\begin{array}{l}\text { Bovine } \\
\text { Bovine } \\
\text { Avian } \\
\text { Porcine }\end{array}$ & $\begin{array}{l}\text { NT } \\
\text { O15 } \\
\text { NT } \\
\text { NT }\end{array}$ & $\begin{array}{l}\overline{-} \\
\pm\end{array}$ & $\begin{array}{c}\mathbf{K}, \mathbf{H} \\
\mathbf{K}, \mathbf{H} \\
\mathbf{K}, \mathbf{H} \\
\mathbf{K}, \mathbf{H}, \mathbf{E} 2\end{array}$ & $\begin{array}{l}\text { FS } \\
\text { FS } \\
\text { FS } \\
\text { FS }\end{array}$ \\
\hline
\end{tabular}

$\mathrm{NT}=$ Untypable; $-=$ colicines not produced; $+=$ colicines produced; V, A, B, K, H, E1, E2, $\mathrm{I}=$ standard colicines; $\mathrm{FS}=$ sensitive to ampicillin, neomycin, chloramphenicol, tetracycline, nitrofurantoin, and sulphafurazole; $\mathrm{R} /=$ resistant; $\mathrm{Su}=$ sulphonamide; $\mathrm{T}=$ tetracycline.

Five colonies of each colonial type of coliform appearing on the MacConkey plate, which contained no antibiotic, were confirmed as Escherichia and serotyped with $O$ antisera $1-25,39$, and 75 as described previously (Cooke et al., 1969). Strains not agglutinated by these antisera are referred to as " untypable".

Colicine production and sensitivity to colicines. Colicine production by the ingested strains was detected by the method of Abbott and Shannon (1958) with E. coli strains Row (a derivative of strain K12) and phi (see Fredericq, 1957) as indicators. These two strains have been said to be sensitive to all colicines (Fredericq, 1948). The colicine sensitivity of the ingested strains to the standard colicines V, A, B, K, H, E1, E2, and I was also demonstrated by the method of Abbott and Shannon.

Ingested strains were tested for colicine activity against other strains of $E$. coli isolated from the faeces during the $2 \mathrm{wk}$ before the ingestion of the strain, while the ingested strain was present in the bowel, and in the week after its disappearance.

Antibiotic-sensitivity test. The antibiotic sensitivity of the ingested strains was determined with Oxoid disks. The antibiotics and the amounts in the disks were ampicillin $25 \mu \mathrm{g}$, nitrofurantoin $200 \mu \mathrm{g}$, neomycin $30 \mu \mathrm{g}$, chloramphenicol $50 \mu \mathrm{g}$, nalidixic acid $30 \mu \mathrm{g}$, streptomycin $25 \mu \mathrm{g}$, tetracycline $50 \mu \mathrm{g}$, sulphafurazole $500 \mu \mathrm{g}$. 


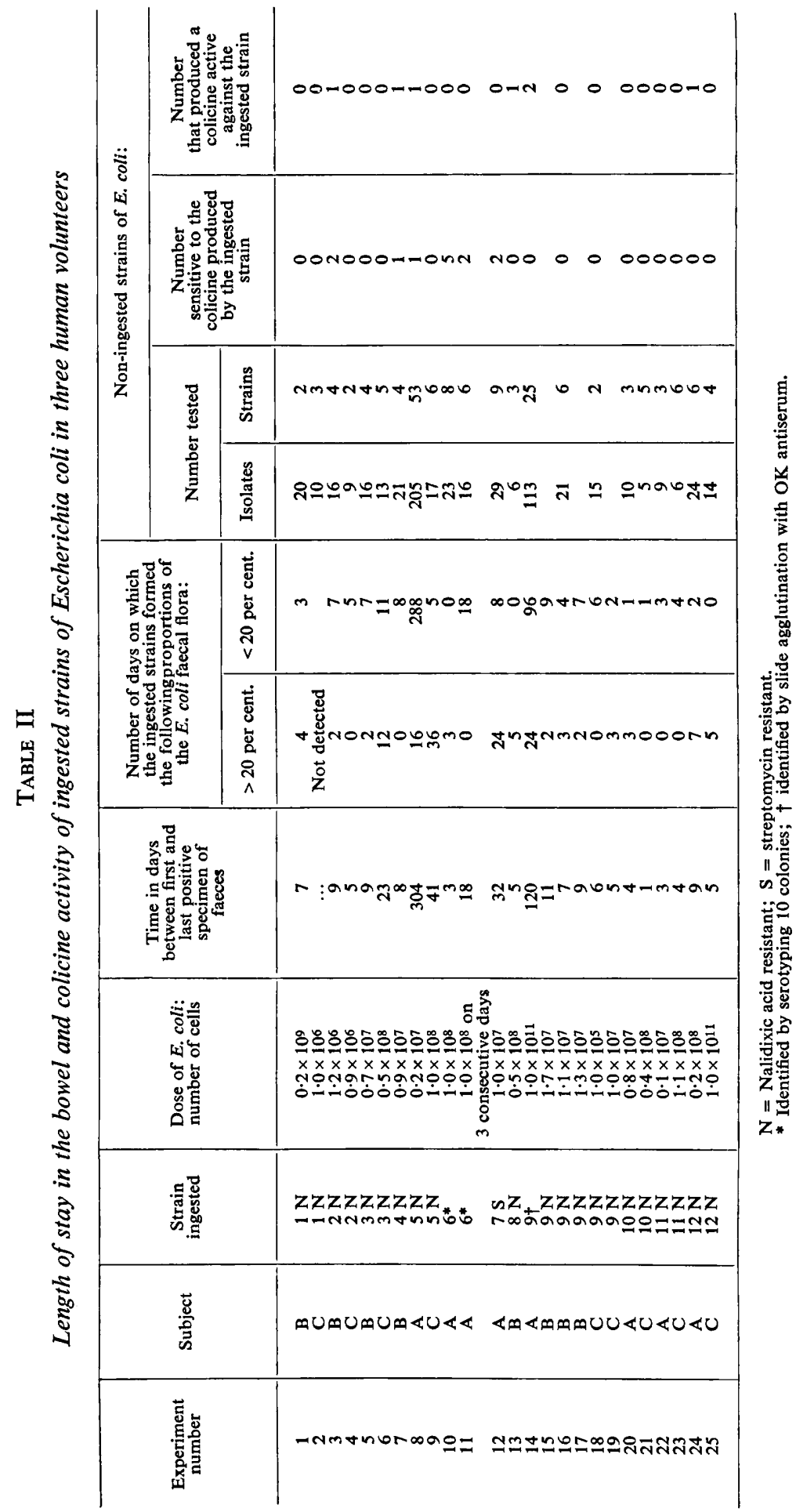




\section{RESULTS}

\section{Fate of ingested strains}

The periods during which the ingested strains were found in faeces are shown in table II. Except in one instance, the ingested strain was found in the next specimen of faeces if this was passed more than $12 \mathrm{hr}$ after ingestion of the strain.

\section{Effect of source of ingested strain}

The periods for which the strains were detected in faeces varied between strains. Most were present for not more than 10 days, but one strain of human

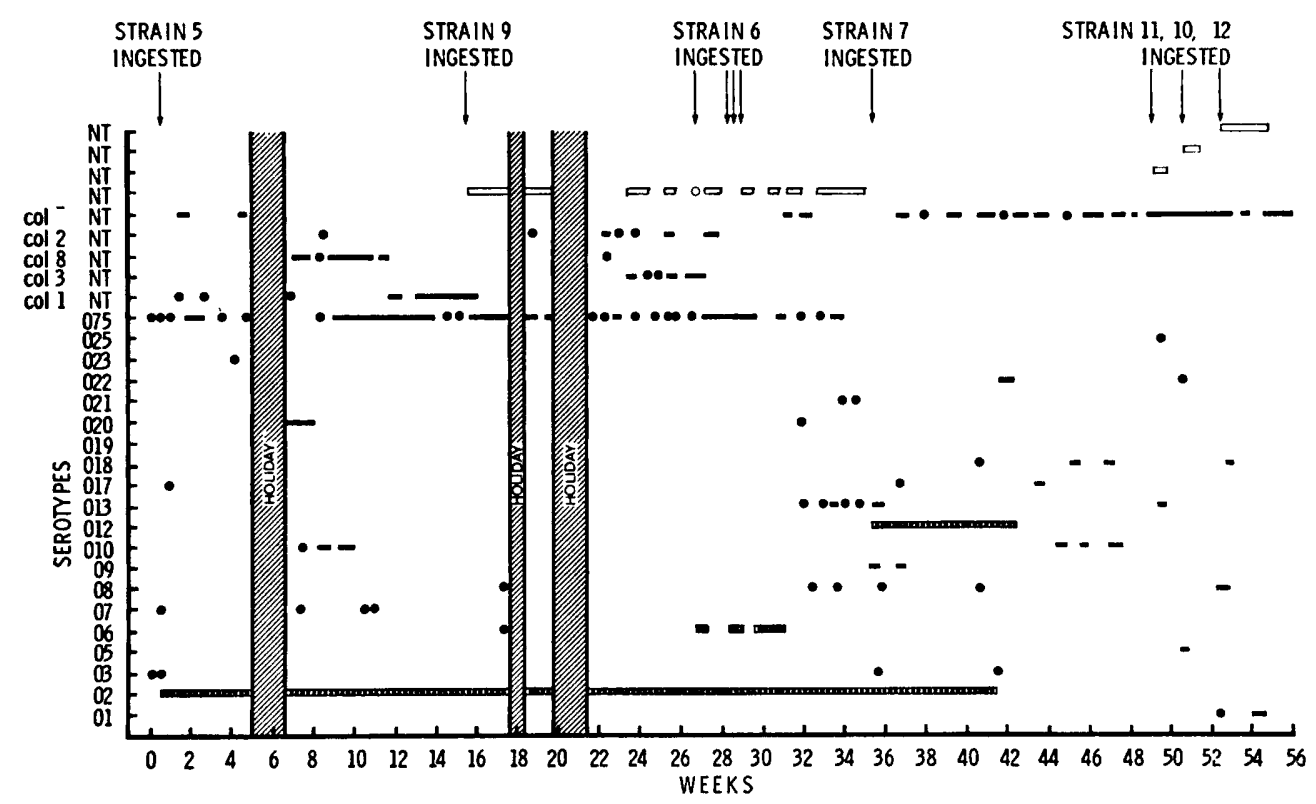

FIGURE.-Isolation of Escherichia coli from the faeces of subject A. шшum ingested human strains; $\varpi$ ingested animal strains; -0 other bowel strains; $O$ and $\bullet$ isolates from single specimens. $\mathrm{NT}=$ Serologically untypable; $\mathrm{col}=$ colicine type. Ingested strain numbers are those indicated in table $\mathbf{I}$.

origin (strain 5, serotype O2) was present in subject $\mathrm{A}$ for 304 days and in subject $C$ for 41 days, and one animal strain (strain 9, untypable) was present in subject $A$ for 120 days after it had been ingested in very large numbers. There was probably no great difference between the persistence in the bowel of human and animal strains. The average times were respectively 9 and 6 days if strains that persisted for more than $1 \mathrm{mth}$ were excluded; the times were calculated in this way in an attempt to eliminate host factors, because three of four strains that persisted more than $1 \mathrm{mth}$ did so in one person.

\section{Behaviour of strains in different persons}

Generally, strains were present for longer in subject A (average 62 days) than in subjects $B$ and $C$ (average 8 and 10 days respectively) though most of 
this difference was due to two strains that remained for long periods. The variety of strains isolated from subject A and the periods for which they persisted are shown in the figure.

\section{Effect of colicines on the establishment of ingested strains}

On some occasions the results were compatible with the view that colicines play a part in determining the fate of ingested $E$. coli; on other occasions this was not so. These findings are summarised below.

\section{Colicines apparently effective in vivo}

Occasions on which an ingested strain displaced a strain resident in the bowel

Expt 10: strain 6, serotype O6, subject A, displaced a rough strain resident for 3 wk.

Expt 12: strain 7, serotype 012 , subject $A$, displaced strain 5, serotype $\mathrm{O} 2$ and serotype 075 , both resident for $35 \mathrm{wk}$.

Occasions on which strains with a short tenure in the bowel were sensitive to the colicine produced by an ingested strain

Expt 3: strain 2, serotype O11, subject B.

Expt 10: strain 6, serotype 06, subject A.

These each produced a colicine active against two other strains of short tenure.

Expt 7: strain 4, serotype O4, subject B.

Expt. 8: strain 5, serotype O2, subject $A$.

These each produced a colicine active against one other strain of short tenure.

Occasions on which an ingested strain was displaced by a newly acquired strain producing a colicine active on it

Expt 13: strain 8, rough, subject $B$, displaced by a rough strain.

Expt 24: strain 12, untypable, subject A, displaced by an untypable strain.

Colicines effective in vitro but not in vivo

Occasions on which an ingested strain failed to displace a resident strain

Expts 10 and 11: strain 6, serotype O6, subject A. This failed to displace strain 5, serotype $\mathrm{O} 2$, and serotype $\mathrm{O} 75$, which were sensitive to the colicine produced by it. However, serotype 075 gradually became resistant to the colicine.

Occasions on which a colicine-sensitive strain established itself in the bowel in the presence of a strain producing a colicine active against it

Expt 7: strain 4, serotype O4, subject B.

Expt 14: strain 9, untypable, subject A.

These displaced untypable strains that produced colicines active against 
them. However, in both cases in-vitro activity could be demonstrated only after 24-hr incubation, but not after $48 \mathrm{hr}$.

Occasions on which strains persisted in the bowel in spite of the presence of strains producing colicines active against them

Expt 3: strain 2, serotype O11, subject B.

Expt 8: strain 5, serotype O2, subject A.

These strains persisted in the bowel despite the acquisition of strains of short tenure producing colicine active against them.

\section{Discussion}

Many workers have reported the difficulty of implanting artificially introduced strains in the human and animal gut. In most experiments on human volunteers, the ingested strains were either not recovered at all, or persisted in the bowel for only a short time (Sears et al., 1950; Sears and Brownlee, 1952; Smith, 1969), and in only one instance was an ingested strain established for over a month (Sears and Brownlee).

In the present study the ingested organisms were recovered from the faeces in all but one instance. On most occasions they did not persist for long in the gut, but in four of 25 experiments the ingested strain did persist for more than a month. In three instances, the ingested strain persisted in the same subject (A), and in the fourth instance the strain that persisted in another subject (C) was also one that persisted in subject A. Differences between human and animal strains in their ability to colonise the human bowel were difficult to assess, but possibly human strains were slightly more able to do so than animal strains; this is similar to the findings reported by Smith. However, we had no difficulty in implanting animal strains, although usually they were present in the bowel for only a few days. On one occasion an animal strain ingested in very large dosage (1011 organisms) persisted in one of the volunteers for 120 days. In Smith's experiments the strains were not ingested in numbers as high as $10^{11}$ at one dose, though $10^{6}$ organisms were ingested daily for 7 days. The difference between these results may be related to individual variation: our experiments were performed on three individuals who differed in their responses. In addition, the strains used were resistant to only one antibiotic whereas Smith worked with multiply-resistant strains.

These results are difficult to interpret, for the part that host factors play in determining the fate of ingested $E$. coli is not known. Such factors do seem to be of importance, because in three of four instances when an ingested strain persisted for over a month in the bowel, it did so in the same subject.

The role of colicines in determining gut ecology was also difficult to assess. In some instances our results were compatible with the view that the ability of a strain to produce a colicine gave it a definite advantage in competing with susceptible strains for the same ecological niche.

On the other hand, some of our results suggested that colicines offered no selective advantage in vivo though they seemed to be effective in vitro. In one 
instance, however, the failure of a colicine-producing strain (strain 6, serotype O6) to displace a colicine-sensitive strain (serotype O75 in subject A) was due to the development of tolerance by the sensitive strain. Seven isolates of serotype O75 recovered during a period of $4 \mathrm{wk}$ were sensitive to the colicine produced by strain 6 . Later isolates of serotype 075 were, however, insensitive to the colicine produced by strain 6 , and it was recovered for 3 wk after strain 6 had disappeared from the faeces. Richardson, Seward and Green (1971) observed that colicine tolerance could be induced by exposure of exponential-phase colicine-sensitive bacteria to low concentrations of colicine.

On two occasions an ingested strain established itself in the gut of the host, so displacing a resident strain that produced a colicine to which the ingested strain was sensitive. The colicine produced in these two instances was ineffective in vivo either because it was labile or because the colicinogenic strain concomitantly produced an inactivator-a possibility suggested by the observation that when these strains were tested in vitro colicine activity was observed only after the producer strain had been incubated for $24 \mathrm{hr}$, but not for $48 \mathrm{hr}$.

One explanation that has been given for the lack of colicine activity in vivo is that colicines are not present in the intestine in adequate concentration to eliminate sensitive organisms. This may be due to their destruction by proteolytic enzymes (Nomura, 1963), inactivation by endotoxins (Braude and Siemienski, 1965; Chang and Hager, 1970), the labile nature of certain colicines (Mennigman, 1965; Kubota et al., 1969), or the concomitant production of an inactivator by colicinogenic strains as was shown in the case of a strain of Serratia marcescens (Foulds and Shemin, 1969). The acquisition of $\mathrm{R}$ factors by intestinal bacteria can lead to a loss of colicinogeny due to elimination of a col factor (Kato, Hanaoka and Amano, 1962; Krčméry, Hurwitz and Fredericq, 1970), or to the development of resistance due to inactivation of colicines by an $\mathrm{R}$ factor-mediated enzyme (Siccardi, 1966; Arai, Ogata and Watanabe, 1969). This may also contribute to the apparent ineffective role of colicines in vivo.

Interactions between the host and the intestinal flora and the relationships that might exist between various intestinal micro-organisms would undoubtedly govern the ecology of the intestinal tract of man. Interpretation of phenomena occurring in such complex situations must therefore be made with reservations. Other limitations to this type of work are the imprecision due to variation between individuals and to the fact that the viable bacterial counts of faecal dilutions, as determined in this study, show only the " net rate of change". As Meynell and Subbaiah (1963) pointed out, it would be of advantage to know the rate of division, the death rate, and the rate at which ingested organisms are excreted into the faeces, in interpreting results from experiments of the type reported here.

In view of the limitations involved, the conditions that determine the fate of ingested E. coli cannot be accurately defined. However, colicines seem to be one of the factors that determine intestinal ecology. One of the most interesting aspects of this investigation was that it was easily possible to produce temporary colonisation of the human gut by animal strains. The importance of this when considering the use of antibiotics in animal husbandry is clear. 


\section{SUMMARY}

Cultures of Escherichia coli of human and animal origin were ingested by three normal persons. It was easy to produce temporary colonisation of the bowel by strains from both sources. Considerable variation in duration of carriage was observed. Some of the results were compatible with the view that colicines determined the fate of ingested strains. In other instances, however, colicines were ineffective in vivo although activity could be demonstrated in vitro.

We are grateful to Professor P. Fredericq, University of Liege, Belgium; Dr Naomi Datta, Postgraduate Medical School, Hammersmith; Dr J. McGeachie, Department of Bacteriology, Glasgow Royal Infirmary; and Dr H. Williams Smith, Animal Health Trust, Stock, Essex, for providing us with some of the strains used, and to Dr F. E. Andre, Riker Laboratories, Hertfordshire, for supplying a freeze-dried preparation in capsule form of one of the strains ingested.

This work formed part of a Ph.D. thesis (University of London) submitted by I. G. T. H., who was in receipt of a Colombo-plan Fellowship.

\section{REFERENCES}

Abbott, J. D., AND Shannon, R. 1958. A method for typing Shigella sonnei, using colicine production as a marker. J. Clin. Path., 11, 71.

Arai, T., Ogata, Y., AND Watanabe, Y. 1969. Episomic resistance factors in Enterobacteriaceae. 40. Colicin resistance and tolerance conferred by $\mathrm{R}$ factors. Medicine Biol., Tokyo (Igaku Seibutsugaku Sokuhōkai), 79, 209, in Japanese.

Braude, A. I., AND SIEMIENSKI, J. S. 1965. The influence of bacteriocins on resistance to infection by Gram-negative bacteria. I. The effect of colicin on bactericidal power of blood. J. Clin. Invest., 44, 849.

Chang, Y.-Y., AND HAGER, L. P. 1970. Inhibition of colicin E2 activity by bacterial lipopolysaccharide. J. Bact., 104, 1106.

CoOke, E. Mary, Ewins, Susan, AND Shooter, R. A. 1969. Changing faecal population of Escherichia coli in hospital medical patients. Br. Med. J., 4, 593.

Cooke, E. Mary, Shooter, R. A., Kumar, Parveen J., Rousseau, S. A., and Foulkes, Alwena L. 1970. Hospital food as a possible source of Escherichia coli in patients. Lancet, 1, 436.

Foulds, J. D., AND Shemin, D. 1969. Concomitant synthesis of bacteriocin and bacteriocin inactivator from Serratia marcescens. J. Bact., 99, 661 .

FredericQ, P. 1948. Actions antibiotiques réciproques chez les Enterobacteriaceae. Revue belge Path. Méd. exp., 19, Suppl. 4, p. 1.

FredericQ, P. 1957. Colicins A. Rev. Microbiol., $11,7$.

Kato, Y., HANAOKA, M., AND Amano, T. 1962. The elimination of a colicinogenic factor by a drug-resistance transferring factor in Escherichia coli K235. Biken J., 5, 77.

KRČmERY, V., HuRWITZ, C., AND FredericQ, P. 1970. Loss of colicinogeny in Escherichia coli strains infected by certain resistance factors. J. Bact., 102, 521 .

Kubota, K., IshiKura, M., Wada, E., AND Gyobu, Y. 1969. Studies on colicin production by Shigella sonnei. I. Basic conditions for the production of colicin. Jap. J. Bact., 24, 631 , in Japanese.

MennigmanN, H. D. 1965. On the nature of the inducible anti-bacterial agent of $E$. coli 15 . Zentbl. Bakt. Parasit Kde, I, Abt. Orig., 196, 207.

Meynell, G. G., and Subbaiah, T. V. 1963. Antibacterial mechanisms of the mouse gut. I. Kinetics of infection by Salmonella typhi-murium in normal and streptomycin-treated mice studied with abortive transductants. Br. J. Exp. Path., 44, 197.

Nomura, M. 1963. Mode of action of colicines. Cold Spring Harb. Symp. Quant. Biol., 28, 315. 
Richardson, H., Seward, B., and Green, C. A. 1971. The survival of colicine-sensitive bacteria when grown with colicine-producing bacteria. J. Med. Microbiol., 4, 63.

Sears, H. J., Brownlee, Inez, AND Uchiyama, J. K. 1950. Persistence of individual strains of Escherichia coli in the intestinal tract of man. J. Bact., 59, 293.

Sears, H. J., AND BrownleE, InEz 1952. Further observations on the persistence of individual strains of Escherichia coli in the intestinal tract of man. J. Bact., 63, 47.

Shooter, R. A., Cooke, E. Mary, Rousseau, S. A., and Breaden, Alwena L. 1970. Animal sources of common serotypes of Escherichia coli in the food of hospital patients. Possible significance in urinary-tract infections. Lancet, 2, 226.

SICCARDI, A. G. 1966. Colicin resistance associated with resistance factors in Escherichia coli. Genet. Res., 8, 219.

SMITH, H. W. 1969. Transfer of antibiotic resistance from animal and human strains of Escherichia coli to resident $E$. coli in the alimentary tract of man. Lancet, 1, 1174.

WirdemanN, B., AND KNOTHE, H. 1969. Untersuchungen über die Stabilität der Koliflora des gesunden Menschen. I. Mitteilung: Über das Vorkommen permanenter und passanter Typen. Arch. Hyg. Bakt., 153, 342. 